\title{
Beyond Discharge Summaries: Communication Preferences in Care Transitions Between Hospitalists and Primary Care Providers Using Electronic Medical Records
}

\author{
Amy Munchhof, MD, PhD ${ }^{1,2}$, Rachel Gruber, MSIO, CCRP3 , Kathleen A. Lane, MS \\ $\mathrm{Na} \mathrm{Bo}, \mathrm{MSPH}^{4}$, and Nicholas A. Rattray, $\mathrm{PhD}^{1,3,5,6}$
}

\begin{abstract}
'Department of General Internal Medicine, Indiana University School of Medicine, Indianapolis, IN, USA; ${ }^{2}$ Hospital Medicine Eskenazi Medical Group, Eskenazi Health Hospital, Indianapolis, IN, USA; ${ }^{3}$ Regenstrief Institute Inc., Center for Health Services Research, Indianapolis, IN, USA; ${ }^{4}$ Department of Biostatistics, Indiana University, Indianapolis, IN, USA; ${ }^{5}$ Veterans Affairs (VA) Health Services Research and Development (HSR\&D) Center for Health Information and Communication, Richard L. Roudebush VA Medical Center, Indianapolis, IN, USA; ${ }^{6}$ Department of Anthropology, Indiana University-Purdue University, Indianapolis, IN, USA.
\end{abstract}

BACKGROUND: Ineffective transitions of care continue to be a source of risk for patients. Although there has been widespread implementation of electronic medical record (EMR) systems, little is currently known about hospitalists' and primary care providers' (PCPs) direct communication preferences at discharge using messaging capabilities in a shared EMR system.

OBJECTIVE: We examined how hospitalists and PCPs with a shared EMR prefer to directly communicate at the time of hospital discharge by identifying preferred modes, information prioritization, challenges, facilitators, and proposed solutions.

DESIGN: A sequential, explanatory mixed methods study with surveys and semi-structured interviews.

PARTICIPANTS: Thirty-eight academic hospitalists and 63 PCPs working in outpatient clinics in a single safety net hospital system with a shared EMR.

MAIN APPROACH: Descriptive statistics were used to analyze survey responses. Interviews were analyzed using immersion/crystallization and a mixture of inductive and deductive thematic analysis.

KEY RESULTS: PCPs preferred direct communication at discharge through a message within the EMR while hospitalists preferred a message within the EMR and email. Qualitative results identified key themes related to patient care and direct communication: value of direct communication, safety, social determinants of health, and clinical judgment. Both groups prioritized direct communication for high-risk medications, pending and follow-up studies, and high-risk patients that hospitalists were concerned about. Overall, both hospitalists and PCPs reported that ensuring patient safety, flagging patients with social challenges, and expressing concerns about patients based on clinical judgment were key communication priorities.

Electronic supplementary material The online version of this article (https://doi.org/10.1007/s11606-020-05786-2) contains supplementary material, which is available to authorized users.

Received August 21, 2019

Accepted March 9, 2020

Published online April 2, 2020
CONCLUSIONS: Hospitalists and primary care providers report considerable overlap in preferences for direct communication at the time of hospital discharge through a shared EMR. Specifically, both groups reported similar concerns regarding patient safety and continuity during transitions. Direct messaging within the EMR could enable "closed loop" communication that helps ensure safe transitions of care for high-risk patients.

KEY WORDS: discharge communication; transitions; hospitalists; primary care providers.

J Gen Intern Med 35(6): 1789-96

DOI: $10.1007 / \mathrm{s} 11606-020-05786-2$

(c) Society of General Internal Medicine 2020

\section{INTRODUCTION}

Effective transitions of care depend on clear communication between hospitalists and primary care providers (PCPs). Even in the era of ubiquitous electronic medical record (EMR) systems, communication may occur through multiple channels, including the EMR system, phone, text messaging, and electronic mail. ${ }^{1,2}$ Ineffective transitions of care are associated with communication breakdowns or inadequate transfers of information. ${ }^{3}$ Post discharge adverse events occur in up to $28 \%$ of discharged patients and one-third of these are preventable. ${ }^{4}$ In particular, communication gaps may lead to adverse drug events, ${ }^{1,}{ }^{4}$ missed results, ${ }^{1}$ and management errors. ${ }^{4}$

Over the past few decades, with the advent of hospitalists, the care of hospitalized patients has become increasingly fragmented between inpatient and outpatient settings. In addition, healthcare systems have transitioned from paper to EMR systems. ${ }^{5}$ Furthermore, patients are often sicker and discharged sooner than they were in the past. ${ }^{6}$ The discharge summary, historically a means of documenting acute care in the hospital, ${ }^{7}$ now serves as the primary and often the only source of communication between hospitalists and PCPs at discharge. ${ }^{5,7,8}$ However, the discharge summary is one-way 
communication, does not close communication loops or clarify ambiguous findings, and is indirect. ${ }^{1,9,}{ }^{10}$ Studies have shown that hospitalists ${ }^{11}$ and PCPs often desire direct communication that supplements the discharge summary. ${ }^{3,12}$

Direct communication has been defined in previous studies as communication from one provider to the other via phone call, page, email, ${ }^{13,14}$ as well as fax and mail. ${ }^{13}$ A past study showed that direct communication occurred only $23 \%$ of the time. ${ }^{13}$ Since then, there has been widespread implementation of EMR systems in inpatient and outpatient settings that has had minimal effect on direct communication between hospitalists and PCPs with one recent study of adult patients showing that direct communication occurred just $36.7 \%$ of the time. $^{15}$

Hospitalists and PCPs spend considerable time in the EMR $^{16-18}$ including documentation, chart review, and order entry. ${ }^{16,17}$ Yet, less is known about hospitalist and PCP use of the EMR for communication with one another. In qualitative studies, hospitalists and PCPs have described the EMR as an ideal tool for sharing information at discharge ${ }^{19}$ and a solution for improving communication at discharge. ${ }^{11}$ In past studies, hospitalists ${ }^{11,19}$ and $\mathrm{PCPs}^{3,19,20}$ have indicated a preference for phone, email, and fax to communicate directly with one another at patient discharge. The pertinent question in the era of the EMR is: have providers' preferences shifted or remained the same?

The primary objective of our study was to assess hospitalists' and PCPs' preferences for using the EMR as a direct communication tool. We used surveys followed by interviews to better understand the communication preferences of PCPs and hospitalists at discharge, focusing on mode of communication and prioritized information intended to augment the discharge summary.

\section{METHODS}

\section{Design and Setting}

We conducted a sequential, explanatory mixed methods ${ }^{21}$ study of hospitalists and primary care providers at an academic center safety net hospital and 10 associated primary health clinics in a large Midwestern city. The hospital and clinics use EPIC as their electronic medical record (EMR) (Epic, Verona, WI). All hospitalists had a clinical teaching role and medical school faculty appointments. The primary care providers consisted of advanced practice providers and physicians; nearly $20 \%$ of physicians had teaching roles training residents. Ethics approval was obtained from the University Institutional Review Board.

\section{Data Collection}

Survey. Two surveys with matching questions for hospitalists and PCPs were developed based on review of literature on care transitions and discharge communication (see Appendix 1, Supplementary Information). 1, 3, 11, 12, 19, 20, 22 Surveys were used to assess modes of direct communication at discharge, which was defined as communication between hospitalists and PCPs through phone call, email, fax,${ }^{13,}{ }^{14}$ text messaging via phone, and messaging within the EMR. Surveys were also used to assess information providers preferred to communicate directly, challenges to direct communication, and satisfaction with direct communication. Questions consisted of ordered response scales, rankings, and open-ended questions. Both surveys were independently pilot tested with a hospitalist and PCP and subsequently refined. The surveys were anonymous and distributed electronically via REDCap, ${ }^{23}$ in person at clinic sites, and at hospitalist meetings. Surveys were open for completion from October 2017 to February 2018.

Interviews. We conducted semi-structured interviews to explore providers' preferences for direct communication at discharge. The interview guide (see Appendix 2, Supplementary

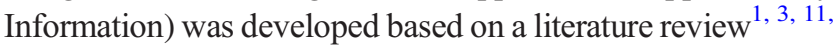
$12,19,20,22$ and preliminary analysis of survey results. It was pilot tested and contained matching questions for hospitalists and PCPs adapted for their practice setting. Participants were recruited via email. Interviews and post-interview impressions were completed by the first author and field notes were made by an observer (MH or JP). Analytic memos ${ }^{24}$ of the interviews were composed by two authors (AM and NR). Interviews lasted 30 to $60 \mathrm{~min}$, were audio recorded, and were transcribed verbatim. A total of 6 hospitalists and 7 PCPs were interviewed; recruitment of participants ceased after thematic saturation was reached.

\section{Analysis}

Descriptive statistics, including means and 95\% confidence intervals for continuous variables and counts and frequencies for categorical variables, were calculated for survey responses. One-way analysis of variance (ANOVA) models were used to assess the association between each categorical variable (age, gender, years in practice, and medical record system, and satisfaction with direct communication) with each type of communication preference ranking in each group.

Interview materials were analyzed using immersion/crystallization, a qualitative research approach that involves multiple reviews of data (immersion) without making prior assumptions about what one will find (crystallization). ${ }^{25}$ Our analysis incorporated deductive categories derived from the questionnaire and inductive themes that emerged from the interviews. ${ }^{26} \mathrm{AM}$ and NR analyzed the transcripts by developing a qualitative codebook and applying codes to interview excerpts through an iterative, consensus-based approach. Each analyst identified portions of transcripts that included data related to care transitions and gave it a provisional name in open coding. The team then compared the provisional codes and differences were reconciled to build an inventory of codes. Themes from the survey were used deductively as a set of codes along with codes that emerged from open coding. The 
resulting codebook was applied to each of the transcripts. ${ }^{24} \mathrm{As}$ coding progressed, discrepancies were resolved in person through weekly face-to-face meetings. Data and coding schemes were revised until thematic saturation was achieved. $^{27}$

\section{RESULTS}

\section{Surveys}

Surveys were completed by 32 PCPs and 26 hospitalists (50.7\% and $68.4 \%$ response rate), all of whom worked in the same health system and used the same EMR. Three-fourths of PCPs and $40 \%$ of hospitalists were female (see Table 1). Just over one-third of PCPs and hospitalists used any EMR in their clinical/residency training while over $70 \%$ in both groups reported receiving no dedicated training in communication at discharge. Over $50 \%$ of hospitalists and PCPs were not satisfied with the current direct communication process at discharge (Table 1).

Table 1 Demographic Characteristics of Survey Participants

\begin{tabular}{|c|c|c|}
\hline & \multirow{2}{*}{$\begin{array}{l}\text { Hospitalists, } N \\
(\%)\end{array}$} & \multirow{2}{*}{$\begin{array}{l}\text { PCPs, } N \\
(\%) \\
(N=32)\end{array}$} \\
\hline & & \\
\hline \multicolumn{3}{|l|}{ Gender } \\
\hline Male & $13(52 \%)$ & $7(24.1 \%)$ \\
\hline Female & $10(40 \%)$ & $22(75.9 \%)$ \\
\hline \multicolumn{3}{|l|}{ Age in years } \\
\hline $30-39$ & $14(58.3 \%)$ & $8(27.6 \%)$ \\
\hline $40-49$ & $6(25.0 \%)$ & $13(44.8 \%)$ \\
\hline $50-59$ & $4(16.7 \%)$ & $7(24.1 \%)$ \\
\hline 60 or older & $0(0 \%)$ & $1(3.5 \%)$ \\
\hline \multicolumn{3}{|l|}{ Clinical training } \\
\hline APP & $1(4.2 \%)$ & $5(17.2 \%)$ \\
\hline $\mathrm{MD} / \mathrm{DO}$ & $23(95.8 \%)$ & $24(82.8 \%)$ \\
\hline \multicolumn{3}{|l|}{ Specialty } \\
\hline Adult NP-certified & $1(4.0 \%)$ & $2(7.0 \%)$ \\
\hline Family medicine & $0(0.0 \%)$ & $8(27.6 \%)$ \\
\hline Internal medicine & $13(52.0 \%)$ & $9(31.0 \%)$ \\
\hline Internal medicine-pediatrics & $10(40.0 \%)$ & $10(34.4 \%)$ \\
\hline Family medicine-internal medicine & $1(4.0 \%)$ & $0(0.0 \%)$ \\
\hline \multicolumn{3}{|l|}{ Years in practice } \\
\hline 0 to 10 & $16(66.7 \%)$ & $13(44.8 \%)$ \\
\hline 11 to 20 & $6(25.0 \%)$ & $7(24.1 \%)$ \\
\hline$>20$ & $2(8.3 \%)$ & $9(31.0 \%)$ \\
\hline \multicolumn{3}{|l|}{$\begin{array}{l}\text { Medical record system used in } \\
\text { training }\end{array}$} \\
\hline Paper record & $0(0.0 \%)$ & $5(17.2 \%)$ \\
\hline Electronic medical record & $9(36.0 \%)$ & $11(37.9 \%)$ \\
\hline Paper and electronic medical & $16(64.0 \%)$ & $13(44.8 \%)$ \\
\hline \multirow{2}{*}{\multicolumn{3}{|c|}{$\begin{array}{l}\text { Dedicated training in } \\
\text { communication at discharge }\end{array}$}} \\
\hline & & \\
\hline Yes & $7(26.9 \%)$ & $8(25.0 \%)$ \\
\hline No & $19(73.1 \%)$ & $24(75.0 \%)$ \\
\hline \multirow{2}{*}{\multicolumn{3}{|c|}{$\begin{array}{l}\text { Satisfaction with direct } \\
\text { communication at discharge }\end{array}$}} \\
\hline & & \\
\hline Satisfied & $8(34.8 \%)$ & $9(32.1 \%)$ \\
\hline Dissatisfied & $13(56.5 \%)$ & $13(46.4 \%)$ \\
\hline Very dissatisfied & $1(4.4 \%)$ & $2(7.1 \%)$ \\
\hline
\end{tabular}

\section{Mode of Direct Communication}

Communication through a message within the EMR was the mode of direct communication preferred by PCPs at patient discharge (Fig. 1). Hospitalists preferred a message within the EMR and email for direct communication at discharge. Both groups preferred message within the EMR over phone call and other forms of communication, including fax, text messaging via cell phone, and paging (Fig. 1). Age, gender, area of specialty, use of EMR, and satisfaction with direct communication were not associated with any mode of communication preferences in either the PCP group or hospitalist group $(p>0.05)$.

\section{Information Prioritized for Direct Communication}

Both hospitalists and PCPs highly prioritized pending studies, recommended follow-up studies, patients with multiple readmissions, patients started on anticoagulation, and a patient the hospitalist is concerned about (Fig. 2). Discontinuing or changing home medications and starting new medications as well as anticoagulation were prioritized by both groups. Information ranked the highest by both groups was a patient the hospitalist is concerned about (MR 4.24 hospitalists (95\% CI 3.96-4.52), MR 4.36 PCPs (95\% CI 4.40-4.67)) (Fig. 2).

\section{Challenges to Direct Communication}

Time constraints and lack of a standardized process for direct communication were ranked highly as challenges to direct communication by hospitalists and PCPs (Fig. 3). The ability to contact PCPs or to be contacted by hospitalists was also identified as a challenge. The absence of personal relationships was ranked lower than the other challenges by hospitalists and PCPs.

\section{Interviews}

Thirteen physicians were interviewed (7 PCPs and 6 hospitalists). We found four themes related to patient care and direct communication: (1) value of direct communication, (2) safety, (3) clinical judgment, (4) social determinants of health; and three themes related to the process of direct communication: (5) challenges, (6) facilitators, (7) potential solutions. Direct quotes from hospitalists and PCPs for all themes can be found in Table 2 and Table 3 .

Value of Direct Communication. PCPs and hospitalists alike valued direct communication at discharge and noted that it allowed key parts of the discharge summary, including critical follow-up items, to be highlighted (Table 3). For hospitalists, direct communication reinforced the goal of teamwork among providers, allowed for communication of information that was difficult to communicate in the discharge summary, and was a means to "close the loop" to help ensure information was not missed. PCPs described direct communication as enhancing 


$\begin{array}{cc}\text { Mode of Communication } & \begin{array}{c}\text { Hospitalist Mean Rank } \\ (95 \% \text { Confidence Limits) }\end{array} \\ \text { Email } & 5.83(5.26,6.40) \\ \text { Message in EMR } & 6.09(5.45,6.72) \\ \text { Phone } & 4.62(3.97,5.26) \\ \text { Phone to Nurse } & 2.78(2.31,3.25) \\ \text { Fax } & 1.91(1.40,2.42) \\ \text { Text Message } & 3.23(2.43,4.02) \\ \text { Page } & 3.38(2.72,4.03)\end{array}$
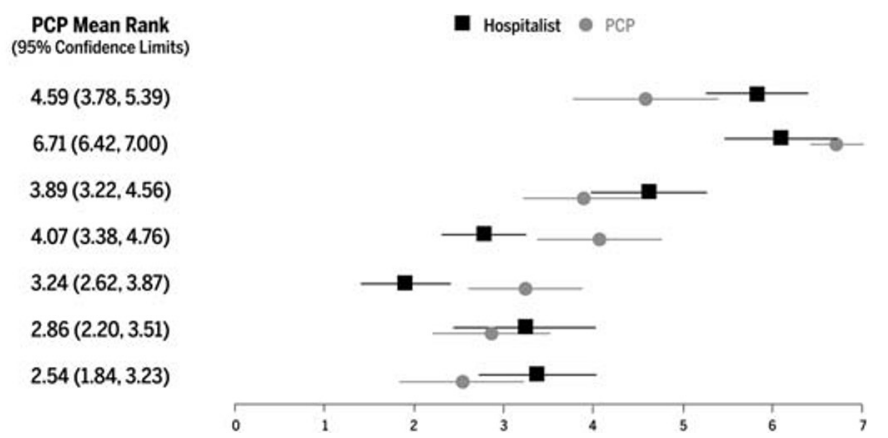

Figure 1 Modes of communication for hospitalists and primary care providers (PCPs) to communicate beyond the discharge summary. Mean ranks with 95\% CI for modes of communication to communicate beyond the discharge summary at patient discharge ranked by hospitalists and primary care providers. Hospitalists are represented by squares and primary care providers (PCPs) are represented by circles.

patient care and increasing patient and provider trust in the system. PCPs also reported they were more likely to have read the discharge summary or pay closer attention to highlighted areas, were more aware of follow-up items, and were more likely to reach out to patients who missed follow-up appointments if they received direct communication.

Safety. Participants from both groups described the importance of direct communication at time of hospital discharge about information that, if missed, could cause patient harm. For example, hospitalists and PCPs described risks associated with medication changes placing a high priority on big changes and high-risk medications such as anticoagulation. Both groups viewed the rationale for medication change(s) as an important element in the discharge summary, yet emphasized highlighting high-risk or major medication changes through direct communication.

Hospitalists and PCPs described the importance of clearly transferring responsibility between providers explaining responsibility can be unclear from the discharge summary alone. Both groups emphasized communicating what is pending, what to do with the result(s), and ensuring that the PCP receives the pending result. When probed, PCPs typically assigned responsibility of pending studies to the ordering provider. Most hospitalists agreed that they were responsible for follow-up of pending studies but also expected follow-up from the PCP. Participants in both groups prioritized direct communication at discharge about pending and follow-up studies to reduce the risk of adverse events that might occur if these are omitted from the discharge summary, or the discharge summary goes unread.

Social Determinants of Health. Beyond safety concerns, study participants identified social factors including social determinants of health (living/home situation, access to healthcare, ability to obtain medications, homelessness, and substance or physical abuse) as high priority for direct communication, especially given the patient population at this safety net hospital. Direct communication at discharge was seen as means for discussing social factors including family dynamics or concerns about caregivers; such concerns are important but challenging to express in the discharge summary.

Clinical Judgment. Clinical judgment, a sense that something is "off" or a "gut instinct," was given high priority for direct communication at discharge by both groups. Several PCPs described wanting direct communication when a hospitalist sensed something was off or had a concern about a patient. Hospitalists preferred direct communication when a patient might "fall through the cracks" or an instinct about a patient, particularly gray areas, where directly communicating with the PCP, who knows the patient better, could be helpful.

Perceived Challenges. For both hospitalists and PCPs, lack of time was a primary barrier to direct communication. PCPs

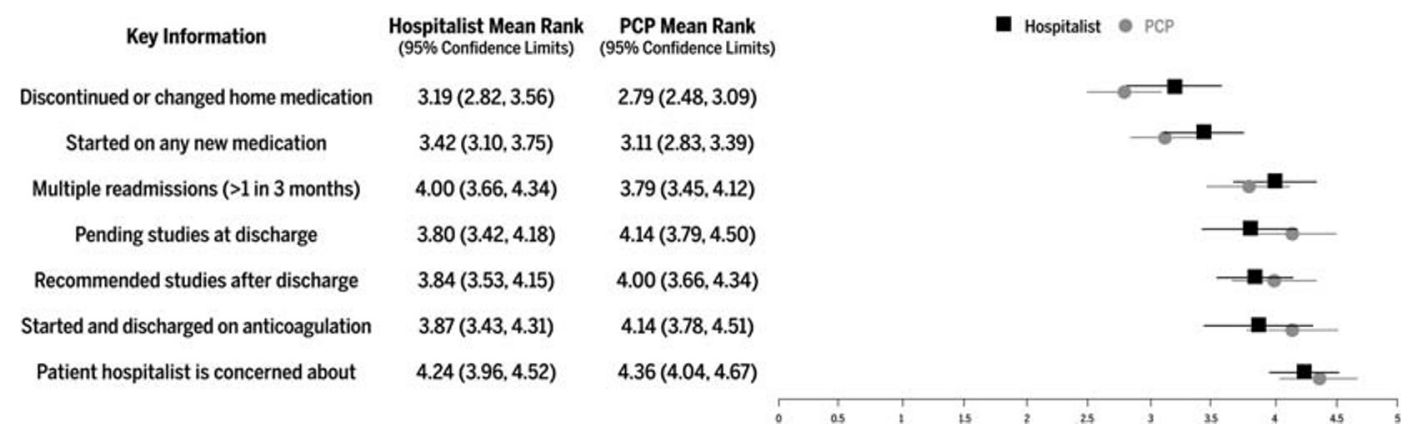

Figure 2 Elements of hospitalization for hospitalists and primary care providers to communicate beyond the discharge summary. Mean ranks with $95 \%$ CI for elements of hospitalization to directly communicate beyond the discharge summary ranked by hospitalists and primary care providers. Hospitalists are represented by squares and primary care providers (PCPs) are represented by circles. 


\begin{tabular}{|c|c|c|}
\hline Challenge & $\begin{array}{l}\text { Hospitalist Mean Rank } \\
\text { (95\% Confidence Limits) }\end{array}$ & $\begin{array}{c}\text { PCP Mean Rank } \\
\text { (95\% Confidence Limits) }\end{array}$ \\
\hline Absence of personal relationship & $2.76(2.42,3.10)$ & $2.31(1.99,2.63)$ \\
\hline Absence of standardized process & $3.24(2.90 .3 .58)$ & $3.00(2.67,3.33)$ \\
\hline Inability to contact or be contacted & $3.25(2.80,3.70)$ & $2.71(2.37,3.06)$ \\
\hline $\begin{array}{l}\text { Absence of dedicated time for } \\
\text { direct communication }\end{array}$ & $3.12(2.78,3.46)$ & $3.37(3.12,3.62)$ \\
\hline Amount of time in work day & $3.44(3.15,3.73)$ & $3.34(2.99,3.70)$ \\
\hline
\end{tabular}

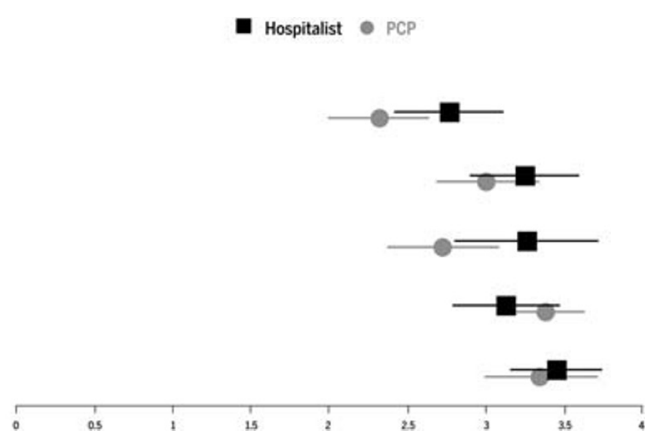

Figure 3 Challenges to communication between hospitalists and primary care providers at patient discharge. Mean ranks with $95 \% \mathrm{CI}$ for challenges to direct communication ranked by hospitalists and primary care providers at time of patient discharge. Hospitalists are represented by squares and primary care providers (PCPs) are represented by circles.

Table 2 Patient Care and Direct Communication

\begin{tabular}{|c|c|c|}
\hline & Hospitalist & PCP \\
\hline $\begin{array}{l}\text { Value of direct } \\
\text { communication }\end{array}$ & $\begin{array}{l}\text { "If I'm concerned that } \\
\text { the patient is not going to } \\
\text { show up for their follow } \\
\text { up and ... I want to make } \\
\text { sure that they're not lost } \\
\text { and make sure the PCP } \\
\text { knows is somebody } \\
\text { should actually call } \\
\text { social work and get } \\
\text { followed up rather than } \\
\text { just letting them fall } \\
\text { away from the system." } \\
\text { (Hosp 1017). }\end{array}$ & $\begin{array}{l}\text { "I think it increases } \\
\text { the patient's trust in } \\
\text { our system when } \\
\text { they know that I've } \\
\text { been in touch with } \\
\text { the hospitalist and } \\
\text { you're not just a } \\
\text { name on a piece of } \\
\text { paper or screen" } \\
\text { (PCP 1133). }\end{array}$ \\
\hline $\begin{array}{l}\text { Safety } \\
\text { • Medications } \\
\text { - Pending and } \\
\text { follow-up studies } \\
\text { - Responsibility }\end{array}$ & $\begin{array}{l}\text { "I wouldn't } \\
\text { [call/message] about } \\
\text { changing the dose of a } \\
\text { statin. [It's] more about } \\
\text { the ones that could be } \\
\text { deadly such as stopping } \\
\text { or adding Plavix or } \\
\text { increasing the dose of the } \\
\text { ACE inhibitor and they } \\
\text { need to have a BMP } \\
\text { followed up. If they're } \\
\text { really high-risk drugs." } \\
\text { (Hospitalists 1024). } \\
\text { "I think probably both of } \\
\text { us... because we are the } \\
\text { ones that ordered the lab } \\
\text { and are responsible for it } \\
\text { initially, but I think there } \\
\text { also needs to be some } \\
\text { responsibility of the PCP } \\
\text { since they're now are } \\
\text { caring for the patient." } \\
\text { (Hosp 1012). }\end{array}$ & $\begin{array}{l}\text { "if you need to } \\
\text { change more than } \\
\text { one medication or if } \\
\text { they're on } 20 \text { units of } \\
\text { insulin [and] they go } \\
\text { home on none, that's } \\
\text { big... I guess it's } \\
\text { bigger medication } \\
\text { changes... stuff that if } \\
\text { they went back to } \\
\text { their old ways would } \\
\text { kill them." (PCP } \\
1128 \text { ). } \\
\text { "So, the biopsy was } \\
\text { done in the hospital, } \\
\text { but the patient left } \\
\text { before the results } \\
\text { came back, are you } \\
\text { going to tell them or } \\
\text { am I supposed to tell } \\
\text { them? What's been } \\
\text { set up? What's the } \\
\text { agreement?" (PCP } \\
1140 \text { ). }\end{array}$ \\
\hline $\begin{array}{l}\text { Social } \\
\text { determinants of } \\
\text { health }\end{array}$ & $\begin{array}{l}\text { "homelessness... ability } \\
\text { to afford and be } \\
\text { compliant with } \\
\text { medications... substance } \\
\text { use, physical abuse... } \\
\text { family members who } \\
\text { may or may not be able } \\
\text { to provide good care." } \\
\text { (Hosp 1010). }\end{array}$ & $\begin{array}{l}\text { "...if there is some } \\
\text { bad social thing } \\
\text { going on... concern } \\
\text { about substance use } \\
\text { disorder... wasn't } \\
\text { previously } \\
\text { recognized... a victim } \\
\text { of domestic } \\
\text { violence... stuff like } \\
\text { that" (PCP 1129). }\end{array}$ \\
\hline Clinical judgment & $\begin{array}{l}\text { "sometimes gut intuition } \\
\text { or instinct...the gray } \\
\text { area... sometimes you } \\
\text { are in... can be good... to } \\
\text { talk with somebody... } \\
\text { who might know the } \\
\text { patient better" (Hosp } \\
\text { 1025) }\end{array}$ & $\begin{array}{l}\text { "... anything that like } \\
\text { you might lose a little } \\
\text { sleep over it at night. } \\
\text { Whenever you have } \\
\text { a gut instinct I think } \\
\text { that's when you } \\
\text { should send a } \\
\text { personal message." } \\
\text { (PCP 1163). }\end{array}$ \\
\hline
\end{tabular}

described not having adequate time to take a phone call or return a page while seeing patients in clinic, while hospitalists described pressures to complete the discharge summary and get patients discharged early. The primary system-level barrier described by both groups was incorrect identification of the PCP in the EMR. Other challenges identified by both groups were "lack of culture" and an inadequate system for direct communication at discharge.

Perceived Facilitators. The primary facilitator of direct communication was having a personal relationship with other providers. Hospitalists and PCPs agreed that not knowing other providers would not prevent them from directly communicating at discharge, but they would be

Table 3 Process of Direct Communication

\begin{tabular}{ll}
\hline \hline & Hospitalists \\
\hline $\begin{array}{c}\text { Challenges } \\
\text { - Culture }\end{array}$ & "Maybe just setting the \\
- Identifying & $\begin{array}{l}\text { happecentent that it should } \\
\text { correct PCP }\end{array}$ \\
& $\begin{array}{l}\text { the culture. I think more } \\
\text { people would be inclined } \\
\text { to do it." (Hosp 1009). }\end{array}$
\end{tabular}

\section{Facilitators - Knowing providers \\ - EMR \\ "I'm much better about direct communication if it's somebody I know." (Hosp 1017). \\ "if we call [the PCP] or page them we're taking them away from another patient. It's also taking our time to page and wait for a call back. So I think it's the EMR messaging that most important." (Hosp 1024).}

Potential solutions - Pop-up message within EMR

- Template within EMR
“... a message when you sign the discharge summary you know this patient was a 30-day readmission please strongly consider sending a message via EMR to their PCP Dr. X." (Hosp 1010).

\section{PCPs}

"They need to do a better job of making sure at least in the EMR it's listed fairly correctly.... They've seen 4 different people in the past year and knowing who their PCP is, is not always easy." (PCP 1116).

"I think it's always easier to communicate with someone you know.” (PCP 1129).

"I think if it somehow became extra work where you had to take phone calls...that would be too cumbersome, but if it's just a brief message to say we did hold this or this is pending, I think that would be good." (PCP 1163).

"you could make a template for it... might make it easier for people to do and to know specifically what information... but we don't want it to turn into as long as discharge.”(PCP 1132). 
more inclined to directly communicate with providers they know. Messaging within the EMR was also viewed as a facilitator of direct communication due to a direct link to patients' charts via medical record numbers, accessibility of messages at any time, and ease of bidirectional messaging.

Potential Solutions. Potential solutions to improve direct communication identified by hospitalists and PCPs included setting an expectation for direct communication to occur, providing more education and/or training on direct communication, and increasing opportunities for providers to meet and get to know one another. Hospitalists suggested that PCPs reply back to messages in the EMR acknowledging receipt as this makes it more likely they will send messages to the PCP in the future. They also described using a scoring system for patients at higher risk of readmission, complex hospital stays, medication changes, or diagnoses to prompt direct communication from the hospitalist to the PCP at discharge. PCPs recommended templates to help structure messages to keep them brief and not become a repeat of the discharge summary.

\section{DISCUSSION}

Using the EMR in transitions of care at discharge can lead to more complete, timely, transfer of information through improvements in the discharge summary, automated notifications of patient discharge to PCPs, and electronic referrals. $2,3,5,9$, ${ }^{28-34}$ The EMR offers tools that facilitate direct communication between hospitalists and PCPs to supplement the discharge summary. Despite widespread EMR implementation, few studies describe providers' preferences for the EMR as means of direct communication. ${ }^{11,19,20}$ Our results show that PCPs and hospitalists prefer to directly communicate with one another through an EMR message. Although our findings may not be surprising, they build on prior work $^{3,19,20}$ by showing that PCPs prefer EMR messages compared to other previously preferred modes including email, phone, and fax. Furthermore, we found that hospitalists prefer messaging within the EMR compared to other modes of communication except email. Interviews corroborated this finding as hospitalists expressed a preference for messaging in the EMR, but at the same time reported feeling more comfortable using email. Our interview results provided insights into providers' preferences for messages within the EMR, which emphasized its ease and accessibility. For instance, PCPs were easily able to access the patient's chart using by a link embedded in the message in the EMR. The ease of bidirectional EMR messaging was more convenient than phone communication. And both groups of providers noted that messaging within the EMR protected patient health information.

Several studies have identified information essential for hospitalists to include in the discharge summary. ${ }^{9}{ }^{29-33}$ Few studies have reported what information hospitalists and $\mathrm{PCPs}^{3}$, 19,20 prioritize for direct communication to supplement the discharge summary. Our results are consistent with a previous study on $\mathrm{PCPs},{ }^{3}$ and by including hospitalists we show that both groups prioritize direct communication for pending studies, multiple readmissions, and high-risk medications. Although our EMR contains a discharge summary template for including pending studies and a complete discharge medication list, both groups highlighted patient safety as the reason for additional direct communication. In addition to safety, our interview results identified three other themes (value of direct communication, social determinants of health, and clinical judgment) reported by hospitalists and PCPs as further rationale for additional direct communication.

Our results build on prior work by showing that hospitalists and PCPs in our surveys placed a very high priority on directly communicating about patients that the hospitalist is "concerned about;" this finding was corroborated by our analysis of the interview data. Concerns a provider has about a patient at discharge often include an intangible dimension that is challenging to express and hard to discern from the discharge summary alone. PCPs respected hospitalists' judgements and appreciated the additional information not included in the discharge summary. It is likewise notable that both hospitalists and PCPs reported that messaging within the EMR could facilitate direct communication about social factors and behavioral and family concerns based on a provider's clinical intuition or familiarity with individual patients - in other words, issues not easily conveyed in the discharge summary.

Consistent with literature on communication, study participants stressed the need to "close" information loops. One known issue is the lack of clarity in the accountability for pending studies at discharge. . $^{9} 11,12,20$ In our study, hospitalists and PCPs underscored the need for clear transfer and acceptance of responsibility for the final result of pending studies, including notifying the patient. Patient safety was highlighted as a rationale for direct communication by both groups as the discharge summary does not provide a means to confirm transfer of responsibility between providers.

Our interview results contained an unexpected finding regarding direct communication. Surprisingly, PCPs expressed that with direct communication, they were more likely to read the discharge summary or pay closer attention to highlighted areas. Future studies may explore the rate at which discharge summaries go unread and if direct communication makes reading the discharge more likely.

This study has several limitations. First, the generalizability of our findings is limited in that it involved a single center at an academic health system and a small sample size of hospitalists and PCPs. Second, findings may be specific to the single EMR system in this hospital system; while this EMR is widely employed in hospitals, other EMR systems may vary in their messaging capabilities. Finally, although our interviews were stopped after thematic saturation was reached, response bias may be present. The interviews were conducted by a hospitalist; this may have introduced social response bias from participants answering in ways they thought would be most desirable to a hospitalist. Recall bias may have also occurred as 
participants may have remembered more recent communication experiences or those associated with strong positive or negative feelings.

Although hospitalists and PCPs practice in different settings, they share similar concerns about ensuring continuity of care across settings, including the need for direct communication of information beyond the discharge summary. Solutions to improve direct communication are challenging, and without systems in place direct communication will continue to occur infrequently. Messaging within the EMR could facilitate direct communication and allow for closed loop communication if the receiver of communication acknowledges receipt to the sender. Discharge workflows should be developed to include direct communication between hospitalists and PCPs for high-risk information that is critical for patient safety as they transition from the hospital back to the primary care setting.

Acknowledgments: We thank Jacob Pell and Monica Huffman for composing field notes during interviews; Kenneth Klotz for assisting with access to primary care clinics for distribution of paper copies of the survey; and Stefanie Sullivan for assisting with access to primary care providers and hospitalists by email for electronic distribution of the surveys and recruitment to participate in interviews. The authors would like to thank the primary care providers and hospitalists for their participation in the surveys and interviews. We also thank Richard Frankel and Ann Cottingham for thoughtful comments on drafts of the manuscript. The authors would like to thank Greg Sachs, Richard M. Frankel, and Ann Cottingham for their mentorship through the Advance Scholars Program for Internists in Research (ASPIRE).

Corresponding Author: Amy Munchhof, MD, PhD; Department of General Internal Medicine Indiana University School of Medicine, Indianapolis, IN, USA (e-mail: ammunchh@iupui.edu).

Funding Information This work was financially supported by the Indiana University School of Medicine Department of Medicine through the Advanced Scholarship Program for Internists in Research and Education (ASPIRE).

\section{Compliance with Ethical Standards:}

Ethics approval was obtained from the University Institutional Review Board.

Conflict of Interest: The authors declare that they do not have a conflict of interest.

\section{REFERENCES}

1. Smith K. Effective communication with primary care providers. Pediatr Clin N Am 2014;61(4):671-679.

2. Walsh C, Siegler EL, Cheston E, et al. Provider-to-provider electronic communication in the era of meaningful use: A review of the evidence. $J$ Hosp Med 2013;8(10):589-597.

3. Sheu L, Fung K, Mourad M, Ranji S, Wu E. We need to talk: Primary care provider communication at discharge in the era of a shared electronic medical record. J Hosp Med 2015;10(5):307-310.

4. Tsilimingras D, Schnipper J, Duke A, et al. Post-discharge adverse events among urban and rural patients of an urban community hospital: a prospective cohort study. J Gen Intern Med 2015;30(8):1164-1171

5. Kattel S, Manning DM, Erwin PJ, Wood H, Kashiwagi DT, Murad MH. Information Transfer at Hospital Discharge: A Systematic Review. $J$ Patient Saf 2016.
6. McLeod LA. Patient transitions from inpatient to outpatient: where are the risks? Can we address them? J Healthc Risk Manag 2013;32(3):13-19.

7. Kripalani S, LeFevre F, Phillips CO, Williams MV, Basaviah P, Baker DW. Deficits in communication and information transfer between hospital-based and primary care physicians: implications for patient safety and continuity of care. JAMA. 2007;297(8):831-841.

8. Robelia PM, Kashiwagi DT, Jenkins SM, Newman JS, Sorita A. Information Transfer and the Hospital Discharge Summary: National Primary Care Provider Perspectives of Challenges and Opportunities. $J$ Am Board Fam Med 2017;30(6):758-765.

9. Snow V, Beck D, Budnitz T, et al. Transitions of Care Consensus policy statement: American College of Physicians, Society of General Internal Medicine, Society of Hospital Medicine, American Geriatrics Society, American College Of Emergency Physicians, and Society for Academic Emergency Medicine. J Hosp Med 2009;4(6):364-370.

10. Rattray NA, Sico JJ, Cox LM, Russ AL, Matthias MS, Frankel RM. Crossing the Communication Chasm: Challenges and Opportunities in Transitions of Care from the Hospital to the Primary Care Clinic. Jt Comm $J$ Gual Saf 2017;43(3):127-137.

11. Jones CD, Vu MB, O'Donnell CM, et al. A failure to communicate: a qualitative exploration of care coordination between hospitalists and primary care providers around patient hospitalizations. J Gen Intern Med 2015;30(4):417-424.

12. Solan LG, Sherman SN, DeBlasio D, Simmons JM. Communication Challenges: A Qualitative Look at the Relationship Between Pediatric Hospitalists and Primary Care Providers. Acad Pediatr 2016;16(5):453459 .

13. Bell CM, Schnipper JL, Auerbach AD, et al. Association of communication between hospital-based physicians and primary care providers with patient outcomes. J Gen Intern Med 2009;24(3):381-386.

14. Ming DY, Stephany AM, Gallis JA, Powers BJ. The Impact of Hospital Health Network Affiliation on Discharge Communication Preferences of Primary Care Providers. J Ambul Care Manage 2018;41(1):80-86.

15. Oduyebo I, Lehmann CU, Pollack CE, et al. Association of self-reported hospital discharge handoffs with 30-day readmissions. JAMA Intern Med 2013;173(8):624-629.

16. Tipping MD, Forth VE, O'Leary KJ, et al. Where did the day go?-a timemotion study of hospitalists. J Hosp Med 2010;5(6):323-328.

17. Arndt BG, Beasley JW, Watkinson MD, et al. Tethered to the EHR: Primary Care Physician Workload Assessment Using EHR Event Log Data and Time-Motion Observations. Ann Fam Med 2017; 15(5):419-426.

18. Sinsky C, Colligan $\mathbf{L}, \mathbf{L i} \mathbf{L}$, et al. Allocation of Physician Time in Ambulatory Practice: A Time and Motion Study in 4 Specialties. Ann Intern Med 2016;165(11):753-760.

19. Harlan G, Srivastava R, Harrison L, McBride G, Maloney C. Pediatric hospitalists and primary care providers: a communication needs assessment. J Hosp Med 2009;4(3):187-193.

20. Leyenaar JK, Bergert L, Mallory LA, et al. Pediatric primary care providers' perspectives regarding hospital discharge communication: a mixed methods analysis. Acad Pediactr 2015;15(1):61-68.

21. Creswell JW, Clark VLP. Designing and conducting mixed methods research. Sage publications; 2017.

22. Greysen SR, Schiliro D, Horwitz LI, Curry L, Bradley EH. "Out of sight, out of mind": housestaff perceptions of quality-limiting factors in discharge care at teaching hospitals. J Hosp Med 2012;7(5):376-381.

23. Harris PA, Taylor R, Thielke R, Payne J, Gonzalez N, Conde JG. Research electronic data capture (REDCap)-a metadata-driven methodology and workflow process for providing translational research informatics support. J Biomed Inform 2009;42(2):377-381.

24. Saldaña J. The coding manual for qualitative researchers. Sage; 2015.

25. Borkan J. Immersion/Crystallization In Crabtree BF \& Miller WL (Eds.), Doing qualitative research (pp. 179-194). In: Thousand Oaks: Sage Publications; 1999.

26. Glaser BG. The constant comparative method of qualitative analysis. Soc Probl 1965;12(4):436-45.

27. Averill JB. Matrix analysis as a complementary analytic strategy in qualitative inquiry. Qual Health Res 2002;12(6):855-866.

28. Hesselink G, Schoonhoven $\mathbf{L}$, Barach $\mathbf{P}$, et al. Improving patient handovers from hospital to primary care: a systematic review. Ann Intern Med 2012;157(6):417-428.

29. Key-Solle M, Paulk E, Bradford K, Skinner AC, Lewis MC, Shomaker $\mathbf{K}$. Improving the quality of discharge communication with an educational intervention. Pediatrics. 2010;126(4):734-739.

30. Halasyamani L, Kripalani S, Coleman E, et al. Transition of care for hospitalized elderly patients-development of a discharge checklist for hospitalists. J Hosp Med 2006; 1(6):354-360. 
31. Myers JS, Jaipaul CK, Kogan JR, Krekun S, Bellini LM, Shea JA. Are discharge summaries teachable? The effects of a discharge summary curriculum on the quality of discharge summaries in an internal medicine residency program. Acad Med 2006;81(10 Suppl):S5-8.

32. Axon RN, Penney FT, Kyle TR, et al. A hospital discharge summary quality improvement program featuring individual and team-based feedback and academic detailing. Am J Med Sci 2014;347(6):472-477.
33. O'Leary KJ, Liebovitz DM, Feinglass J, et al. Creating a better discharge summary: improvement in quality and timeliness using an electronic discharge summary. J Hosp Med 2009;4(4):219-225.

34. O'Malley AS, Grossman JM, Cohen GR, Kemper NM, Pham HH. Are electronic medical records helpful for care coordination? Experiences of physician practices. J Gen Intern Med 2010;25(3):177-185.

Publisher's Note: Springer Nature remains neutral with regard to jurisdictional claims in published maps and institutional affiliations. 